\title{
Marco normativo de la distribución comercial en Derecho Español y propuestas de regulación
}

\author{
Daniel Vázquez Albert
}

Universidad de Barcelona

dvazquez@ub.edu

Fecha de recibido: octubre 2016 / Fecha de aprobación: febrero 2017

\section{Resumen}

El sector de la distribución comercial convive desde hace tiempo con un fuerte décalage entre su excelencia empresarial y su deficiencia normativa. Desde la perspectiva empresarial, se trata de un sector dinámico, innovador y competitivo. Pero desde la perspectiva jurídica, adolece de graves carencias normativas que se resumen en la ausencia de un régimen jurídico exhaustivo, sistemático, nítido, transparente, eficaz y flexible. El presente trabajo analiza estas carencias sobre la base del marco normativo actual, las nuevas propuestas de regulación y las tendencias en el ámbito internacional, para finalizar con algunas reflexiones críticas y propuestas de solución.

\section{Palabras Clave}

Contratos / distribución / agencia / libre competencia / soft law

\section{Abstract}

The commercial distribution sector coexists long with a strong décalage between business excellence and regulatory deficiency. From a business perspective, it is a dynamic, innovative and competitive sector. But from a legal perspective, it has serious regulatory deficiencies sumarized in the absence of a comprehensive, systematic, clear, transparent, efficient and flexible legal regime. This paper analyzes these gaps on the basis of the current regulatory framework, new regulatory proposals and trends in the international arena, ending with some critical reflections and proposed solutions.

\section{Key words}

Contracts / distribution / agency / free competition / soft law 
I. El dilema sobre la necesidad de regular los contratos de distribución. I.I. Excelencia empresarial vs. deficiencia normativa. 1.2. Asimetría negocial y elevada conflictividad. 2. Normativa aplicable. 2. I. Normativa contractual: la Ley sobre el contrato de agencia. 2.2. El problema de la aplicación analógica de la normativa de agencia. 2.3. Normativa no contractual. 3. Propuestas de regulación: ¿hacia una Ley de contratos de distribución? 3.I. Una década repleta de proyectos fallidos (2006-2016). 3.2. Claves de la regulación proyectada: ¿normas imperativas o dispositivas? 4. Tendencias normativas en el ámbito internacional. 4.I. Visión general del Derecho comparado. 4.2. Armonización internacional del Derecho de contratos mediante soft law. 5. Reflexión final.

\section{El dilema sobre la necesidad de regular los contratos de distribución}

\section{I. Excelencia empresarial vs. deficiencia normativa}

El sector de la distribución comercial convive desde hace tiempo con un fuerte décalage entre, su excelencia empresarial y su deficiencia normativa. Por un lado, desde la perspectiva empresarial, todos los estudios muestran que se trata de un sector dinámico, innovador y competitivo, que posee un enorme impacto en la economía de acuerdo con diversos parámetros (facturación, empresas del sector, trabajadores empleados, consumidores, etc.), que se canaliza a través de una rica y variada pléyade de sistemas y modalidades contractuales, y que además se halla en constante expansión estando en la vanguardia de la internacionalización de los negocios (vid., destacadamente, el exhaustivo "Informe sobre la problemática de los contratos de distribución” del Ministerio de Industria, Turismo y Comercio español, de marzo de 2009).

En contraste, desde la perspectiva jurídica, el panorama no es nada halagüeño, puesto que el sector de la distribución comercial adolece de graves carencias normativas que se resumen en la ausencia de un régimen jurídico exhaustivo, sistemático, nítido, transparente, eficaz y flexible que responda a las expectativas que genera el dinamismo de este sector, tarea que, vaya por delante, no es nada sencilla, sino más bien compleja. Para empezar, este sector, caracterizado por su creciente internacionalización, topa de entrada con el carácter esencialmente local y segmentado de la normativa aplicable, lo que a menudo supone una barrera de entrada a nuevos mercados. A pesar de los denodados esfuerzos que Estados y organizaciones internacionales desarrollan para conseguir una armonización del derecho de los negocios, este horizonte se encuentra todavía lejano.

Ciertamente, estas deficiencias se deban probablemente a que la moderna distribución es un fenómeno relativamente reciente que el Derecho debe todavía asimilar. Pero la realidad es que hoy por hoy son los operadores y los tribunales (ordinarios o arbitrales) sobre quienes recae el peso de encontrar soluciones jurídicas ante esta inconsistencia normativa, unos ex ante mediante la contratación y otros ex post una vez surge el conflicto, pero enfrentándose ambos a sus propias limitaciones, entre las que cabe mencionar los costes de negociación de los operadores, y la falta de especialidad de determinados tribunales, así como la frecuente volatilidad de los criterios jurisprudenciales. En este contexto, el régimen jurídico de la distribución, en lugar de ser una solución a los problemas empresariales se ha 
convertido en un problema en sí mismo, que ha fomentado el incremento de la conflictividad. Todo ello sin que el legislador se atreva de forma decidida a dar un paso al frente para aportar la seguridad jurídica que el sector reclama.

Uno de los problemas jurídicos que está causando mayor desazón es la ausencia de una normativa que regule con carácter general los contratos de distribución. Es preciso aclarar de inmediato que esto no significa en absoluto que estos contratos se hallen huérfanos de toda regulación. Antes al contrario, y como se desarrollará más adelante, existen aunque con cierta dispersión abundantes normas de diverso signo que son directamente aplicables a los mismos, e incluso existen leyes específicas que regulan alguna de sus modalidades (particularmente, la Ley 12/1992, de 27 de mayo, sobre el contrato de agencia).

Pero a pesar de existir una regulación específica del contrato de agencia y diversas normas aplicables a los contratos de distribución en general, la atipicidad o carencia de reglas que queremos subrayar se refiere más concretamente a la ausencia de normas que regulen con carácter general las diferentes modalidades de contratos de distribución y, en especial, las relaciones jurídicas entre los dos principales actores de estos contratos: proveedores (o fabricantes) y distribuidores.

\section{I.2. Asimetría negocial y elevada conflictividad}

Ciertamente, este desfase entre realidad y regulación no necesariamente resulta problemático, pues son múltiples los sectores y las actividades que se desarrollan con normalidad sin necesidad de reglas específicas, las cuales a veces incluso podrían llegar a enturbiar su correcto funcionamiento. Pero en el caso de la distribución comercial la ausencia de regulación es, cuando menos, llamativa, teniendo en cuenta dos elementos característicos de los contratos de distribución que además afectan a dos momentos clave de la contratación: de un lado, la frecuente asimetría negocial de las partes que condiciona la formación del contrato; $y$, de otro, la elevada conflictividad que habitualmente rodea la extinción del contrato y que a menudo desemboca en litigiosidad.

En primer lugar, en cuanto a la asimetría negocial, debe tenerse en cuenta que resulta habitual que en los contratos de distribución nos encontremos con un proveedor que responde a la categoría de una gran empresa, a menudo de carácter multinacional, que busca seleccionar con criterios prestablecidos un colaborador local que generalmente posee las características de una pequeña o mediana empresa. Además, el proveedor suele querer generar una red integrada de distribuidores, lo que se traduce en la búsqueda de la mayor uniformidad posible en las condiciones contractuales aplicables a cada distribuidor, sea o no mediante el recurso a condiciones generales de la contratación. Por si fuera poco, es frecuente en la práctica que estas relaciones comerciales no se formalicen mediante un contrato escrito, lo que deja indeterminadas las obligaciones de las partes, que a menudo se concretan unilateralmente por parte del proveedor. En esta tesitura, es frecuente que el proveedor quiera imponer sus condiciones a los distribuidores y efectivamente lo consiga gracias a su mayor poder negocial, lo que facilita la existencia de abusos por parte del proveedor en detrimento de los distribuidores.

Sin embargo, es preciso tener en cuenta que esta estructura contractual no es la única posible, pues de hecho puede producirse justo la contraria. En determinados supuestos, son los distribuidores quienes pueden tener un alto poder de negociación, fruto de su posición estratégica, su inmediatez con la clientela y su fortaleza económica. Tal es el caso de las grandes empresas de distribución minorista, que además suelen comercializar productos o servicios bajo sus propias marcas de distribuidor (marcas blancas) y 
pueden negociar de tú a tú con los fabricantes de las grandes marcas e incluso pueden imponer condiciones a pequeños fabricantes. En tales supuestos, el riesgo de posibles abusos negociales se produciría en detrimento de los fabricantes, no de los distribuidores.

En segundo lugar, los contratos de distribución plantean también un riesgo de alta conflictividad, siendo sin lugar a dudas uno de los ámbitos más litigiosos de la contratación mercantil. Como es sabido, la litigiosidad en este ámbito se concentra sobre todo en los casos, muy frecuentes en la práctica, de extinción de la relación contractual, en los que proveedor y distribuidor suelen discutir agriamente sobre cómo liquidar dicha relación contractual después de largos años de estrecha colaboración y, más concretamente, sobre la procedencia o no de las indemnizaciones que la terminación del contrato puede generar, entre las que destaca la controvertida indemnización por clientela.

Tanto el riesgo de abusos, como la abundante e intensa litigiosidad parecen abonar el terreno a una reacción legislativa. $\mathrm{Y}$, de hecho, esta situación ha generado una sensibilidad normativa que en la última década ha desembocado en la presentación de múltiples proyectos de regulación de los contratos de distribución, algunos de los cuales han llegado a formalizarse como proyectos de ley, hasta el punto de que uno de esos proyectos ha culminado su tramitación parlamentaria para ser aprobado como ley, aunque como veremos ha sido abortado con celeridad dejando la reforma en suspenso.

Ninguno de estos proyectos ha fructificado a causa de la pugna entre los dos sectores económicos enfrentados en esta materia (proveedores y distribuidores). Los distribuidores pretenden impulsar una regulación que, en la línea de la Ley sobre contratos de agencia, les ofrezca en términos imperativos una protección similar a la del agente. Por su parte, los proveedores se oponen frontalmente a toda reforma defendiendo el actual statu quo, porque éste les ofrece un amplio margen de libertad negocial que les permite pactar contractualmente las condiciones más favorables en ausencia de normas legales tuitivas de los distribuidores.

Paralizado ante la disputa entre estas dos posiciones contrapuestas, el Gobierno no se ha atrevido a dar un paso adelante promoviendo una solución legal que encuentre el equilibrio entre los dos extremos. El silencio legislativo ha hecho que la jurisprudencia haya ganado importancia. En esta labor, los tribunales han tomado como punto de referencia la antes mencionada Ley de contrato de agencia, aplicándola por analogía a los casos de contratos de distribución.

Resulta fundamental remarcar que esta problemática no solo se plantea en España, sino que posee carácter universal. En la mayor parte de los países, especialmente en los países europeos, que por normativa comunitaria cuentan con leyes reguladoras de contrato de agencia similares a la nuestra, dicha problemática suele solucionarse por la vía de la aplicación analógica del régimen de agencia, sin que se plantee como solución la aprobación de una legislación específica de los contratos de distribución.

Sobre la base de todo lo anterior, el presente trabajo pretende ofrecer una visión panorámica del marco normativo actual de los contratos de distribución y de las propuestas de reforma. Así, se realizará, en primer lugar, un breve repaso de la normativa aplicable, tanto la contractual (especialmente la Ley de contrato de agencia, en adelante LCA), y el problema de su aplicación analógica), como la no contractual (principalmente las reglas de la competencia, de comercio interior y de internacional privado). En segundo lugar, se hará una referencia a las diversas propuestas normativas planteadas en España y las claves de su contenido, con especial referencia a su configuración como norma imperativa o dispositiva. 
Finalmente, se abordarán las tendencias normativas en el ámbito internacional, dando una visión general de la situación en el Derecho comparado y de la armonización internacional del Derecho de contratos. Conviene señalar que tanto la normativa aplicable como la proyectada se analizarán desde una perspectiva panorámica, sin entrar al detalle, que será tratado en los correspondientes trabajos de esta obra relativos a los distintos aspectos puntuales. Todo ello para finalizar reflexionando en sede de conclusiones sobre las carencias de la normativa actual y las aportaciones que ofrecen las propuestas de reforma, no solo como tales, sino como criterio interpretativo a utilizar por los tribunales en la resolución de casos y como criterio negocial a utilizar por las partes en la negociación y redacción de los contratos.

\section{Normativa aplicable}

\section{I. Normativa contractual: la Ley sobre el contrato de agencia}

Los contratos de distribución se hallan sujetos, como todos los contratos, a las normas generales reguladoras de las obligaciones y contratos, contenidas en el Código civil (arts. 1088 y ss.). Además, según se ha avanzado, el contrato de agencia es la única de entre las principales modalidades de contratos mercantiles de distribución que posee una normativa legal específica que regula el contenido y la extinción del contrato. Ciertamente, el contrato de comisión mercantil posee también una regulación legal contenida en el Código de comercio (arts. 244 y ss.), pero se trata de una modalidad residual en la distribución comercial, pues ésta suele estructurarse en la actualidad sobre la base de relaciones permanentes con el proveedor en régimen de integración en una red de distribución, mientras que el contrato de comisión está diseñado sobre la base de operaciones aisladas y esporádicas.

La LCA, tiene su origen en la Directiva 86/653/CEE del Consejo, de 18 de diciembre de 1986, relativa a la coordinación de los derechos de los Estados Miembros en lo referente a los agentes comerciales independientes, que nació con la intención de armonizar las distintas regulaciones nacionales existentes en la materia a fin de facilitar la libertad de establecimiento y de prestación, y asegurar así el correcto funcionamiento del mercado único de la representación comercial. Aunque ni la Directiva ni la Ley lo indican expresamente en sus respectivas exposiciones de motivos, ambas incorporan una elevada protección de los agentes comerciales bajo su consideración de parte débil del contrato.

Es por esta razón que ambas se configuran en términos imperativos, limitando la autonomía de la voluntad de las partes, lo que supone una excepción a la regla general aplicable en derecho de contratos. Se trata además de una característica que se halla más marcada en la Ley, pues ésta indica que sus preceptos poseen carácter imperativo a menos que expresamente se disponga otra cosa (art. 3).

Tanto en la Directiva como en la Ley, el grueso de sus normas se refiere a tres aspectos sensibles como son los derechos y obligaciones de las partes, la remuneración del agente y, sobre todo, la extinción del contrato, con particular referencia a las indemnizaciones que derivan de la misma. Entre estas indemnizaciones, la llamada indemnización por clientela es sin duda la más relevante por su trascendencia económica y jurídica.

Es interesante mencionar que en 2014 la Directiva de agentes comerciales fue objeto de un proceso de evaluación bajo el Programa de la Comisión Europea denominado REFIT, dirigido a simplificar la normativa europea. Después de consultas con los Estados Miembros y con los sectores interesados, en 
el Informe de evaluación de 2015 se concluyó que la Directiva debía mantenerse, porque había mostrado ser eficaz en la consecución del objetivo de facilitar las operaciones transfronterizas de representación comercial; ser eficiente al conseguir sus objetivos generando beneficios sin crear costes excesivos; aportar valor añadido al facilitar el crecimiento sostenido del sector; y ser coherente con otras políticas comunitarias. Se trata del documento "Evaluation of the Council Directive on the coordination of the laws of the Member States relating to self-employed commercial agents" (Directive 86/653/EEC), SWD (20I5), Bruselas, 16 de julio de 2015.

Sin embargo, aun reconociendo que con carácter general la Directiva y la Ley han cumplido correctamente con sus objetivos y han aportado seguridad jurídica al sector, debería también admitirse que cumplidos treinta años desde la aprobación de la Directiva, y casi veinticinco desde la aprobación de la Ley, durante todo este tiempo se ha producido una evolución no solo empresarial, sino también normativa que justifica una actualización de ambas normas, aunque sea puntual. En el terreno empresarial, basta pensar con el comercio electrónico y, en general, en el uso de las nuevas tecnologías a efectos comerciales, así como en la creciente globalización, sin perjuicio de cuestiones prácticas a las que la jurisprudencia se ha afrontado con soluciones no siempre uniformes. $Y$ en el plano normativo es necesario mencionar las distintas propuestas normativas nacionales e internacionales, que como luego se comentarán, han enriquecido los materiales y criterios jurídicos a disposición del legislador.

\subsection{El problema de la aplicación analógica de la normativa de agencia}

Ante la ausencia de una regulación legal de los contratos de distribución y la elevada litigiosidad del sector, los tribunales han optado con carácter general por una aplicación analógica del régimen legal del contrato de agencia a los contratos de distribución en general. Esta solución no ha estado exenta de problemas, puesto que durante un tiempo la jurisprudencia al respecto se ha mostrado dubitativa, hasta que una Sentencia núm. I392/2008 del Tribunal Supremo, Sala I a de lo Civil, de I5 de enero de 2008, dictada en Pleno (ponente: Francisco Marín Castán), pareció cerrar la cuestión admitiendo expresamente la aplicación analógica. Se trata de una doctrina jurisprudencial que se mantiene viva en la actualidad, como demuestra la reciente Sentencia núm. 163/2016 del Tribunal Supremo, Sala Ia , de lo Civil, 16 de marzo de 2016 (ponente: Pedro José Vela Torres).

En principio, la jurisprudencia favorable a la aplicación analógica favorece los intereses de los distribuidores, en la medida en que les otorga una protección similar a la concedida a los agentes. Sin embargo, esta aplicación analógica presenta dos características relevantes que limitan su alcance, lo que esencialmente beneficia a los fabricantes.

En primer lugar, no opera de forma automática y mimética, sino que exige valorar en cada caso que efectivamente exista una identidad de razón entre el supuesto de hecho enjuiciado relativo al contrato de distribución y el supuesto de hecho regulado por la Ley del contrato de agencia, de modo que si bien en la mayoría de los casos se admite la analogía no ocurre así en todos los supuestos, lo que plantea a los operadores una cierta inseguridad jurídica en cuanto a la previsibilidad sobre el alcance real de dicha analogía.

Es en este punto donde pueden ganar relevancia las importantes diferencias existentes entre el contrato de agencia y el de distribución exclusiva, pues en el primer caso el agente actúa en nombre y por cuenta 
del principal, mientras que el distribuidor lo hace en nombre y por cuenta propios, pues compra los productos al fabricante para revenderlos al consumidor. Este dato resulta clave a los efectos de determinar cuestiones tan relevantes a los efectos de la aplicación analógica como quién asume el riesgo de la actividad en caso de pérdida, impago o falta de comercialización de los productos distribuidos; así como quien entabla la relación jurídica con los clientes. En el contrato de distribución es el distribuidor quien asume el riesgo y es contraparte respecto al cliente, mientras que en el contrato de agencia, es el principal y no el agente quien asume el riesgo y tiene la relación con el cliente.

En segundo lugar, y de forma todavía más importante, la analogía se configura como analogía débil, no fuerte, lo que significa que solo se aplica en defecto de pacto en contra, de modo que lo que las partes hayan convenido en el contrato será aplicable aunque sea contrario a lo que establece la Ley de contrato de agencia.

\subsection{Normativa no contractual}

Además de la normativa contractual, los contratos de distribución se hallan sujetos a distintas normas, entre otras, las relativas a la competencia, el comercio interior, la propiedad industrial, concursales, penales, internacionales, etc. Por razones de espacio, se hará referencia sólo a alguna de ellas por su mayor impacto en la distribución.

\section{a) Normativa de la competencia}

En relación al derecho de la competencia, su aplicación a los contratos de distribución deriva fundamentalmente de la frecuente incorporación a los mismos de cláusulas que restringen la libre competencia en el mercado, a menudo porque limitan la capacidad de decisión de los distribuidores sobre la base del control que los proveedores pretenden ejercer sobre los mismos. Piénsese, típicamente, en las obligaciones de exclusiva territorial, o en la fijación (o recomendación) de precios.

Estas cláusulas estarían en principio prohibidas por el art. I0 I del Tratado de Funcionamiento de la Unión Europea (UE)I al ser contrarias a la libre competencia, pero la propia UE aprueba Reglamentos de

\footnotetext{
' Art. I0I TFUE: "I. Serán incompatibles con el mercado interior y quedarán prohibidos todos los acuerdos entre empresas, las decisiones de asociaciones de empresas y las prácticas concertadas que puedan afectar al comercio entre los Estados miembros y que tengan por objeto o efecto impedir, restringir o falsear el juego de la competencia dentro del mercado interior $\mathrm{y}$, en particular, los que consistan en: a) fijar directa o indirectamente los precios de compra o de venta u otras condiciones de transacción; b) limitar o controlar la producción, el mercado, el desarrollo técnico o las inversiones; c) repartirse los mercados o las fuentes de abastecimiento; d) aplicar a terceros contratantes condiciones desiguales para prestaciones equivalentes, que ocasionen a éstos una desventaja competitiva; e) subordinar la celebración de contratos a la aceptación, por los otros contratantes, de prestaciones suplementarias que, por su naturaleza o según los usos mercantiles, no guarden relación alguna con el objeto de dichos contratos. 2. Los acuerdos o decisiones prohibidos por el presente artículo serán nulos de pleno derecho. 3. No obstante, las disposiciones del apartado I podrán ser declaradas inaplicables a: - cualquier acuerdo o categoría de acuerdos entre empresas, - cualquier decisión o categoría de decisiones de asociaciones de empresas, - cualquier práctica concertada o categoría de prácticas concertadas, que contribuyan a mejorar la producción o la distribución de los productos o a fomentar el progreso técnico o económico, y reserven al mismo tiempo a los usuarios una participación equitativa en el beneficio resultante, $y$ sin que: a) impongan a las empresas interesadas restricciones que no sean indispensables para alcanzar tales objetivos; b) ofrezcan a dichas empresas la posibilidad de eliminar la competencia respecto de una parte sustancial de los productos de que se trate."
} 
exención por categorías para determinados acuerdos verticales, que son aplicables a los contratos entre fabricantes y distribuidores. En su última versión, el Reglamento (UE) $n^{\circ} 330 / 2010$ de la Comisión, de 20 de abril de 2010, siguiendo la línea del anterior, autoriza las restricciones habitualmente contenidas en dichos contratos, siempre que no resulten especialmente graves para la competencia y que las partes contratantes no ostenten más del treinta por ciento del mercado de referencia de los bienes o servicios distribuidos. Dada la habitual dispersión del mercado de la distribución, en la inmensa mayoría de los contratos no se superará el mencionado umbral. Entre las restricciones especialmente graves cabe mencionar la imposición de precios de venta mínimos o fijos; o la prohibición de realizar ventas pasivas a favor de terceros con residencia fuera del territorio exclusivo.

El Derecho de la libre competencia ha ganado importancia práctica, puesto que las autoridades de la competencia han sido particularmente activas en su implementación en el sector de la distribución, imponiendo con cierta frecuencia elevadas sanciones por su incumplimiento. Uno de los ámbitos donde han sido más activas es el de los hidrocarburos, en los que incluso han promovido reformas legales a fin de establecer normas de la competencia más estrictas para combatir la concentración empresarial existente en este sector y eliminar barreras de entrada mediante contratos de abanderamiento de larga duración y fijación de precios mediante recomendaciones que en la práctica operaban de forma vinculante.

Otro de los ámbitos donde el Derecho de la competencia ha tenido una especial incidencia ha sido el sector de la distribución de vehículos a motor. En este sector rige un Reglamento especial de exención por categorías, que pretende fomentar la competencia ante las peculiaridades de un mercado caracterizado por la gran dependencia de los distribuidores respecto a los fabricantes. Se trata del Reglamento (UE) núm. 46I/2010, de la Comisión, de 27 de mayo de 2010, relativo a la aplicación del artículo I0I, apartado 3, del Tratado de Funcionamiento de la Unión Europea a determinadas categorías de acuerdos verticales y prácticas concertadas en el sector de los vehículos de motor.

Más allá del Derecho de la libre competencia, pero dentro del ámbito del Derecho de la competencia en general, cabe reseñar que también la Ley $3 / 1991$, de competencia desleal, de 10 de enero, es susceptible de aplicarse en los contratos de distribución. Los casos más frecuentes están vinculados a los conflictos que surgen entre proveedor y distribuidor con motivo de la terminación del contrato. Entre los actos desleales que suelen denunciarse se hallan los de confusión, denigración, captación desleal de clientela, denuncia unilateral abusiva. Sin embargo, hay que señalar que los tribunales son bastante reticentes a declarar la deslealtad de las conductas denunciadas, siguiendo el criterio liberalizador de nuestra normativa, que parte de la regla general de libre competencia tipificando restrictivamente los ilícitos desleales.

\section{b) Normativa de comercio interior}

La distribución comercial se halla también sujeta a las normas de comercio interior, contenidas principalmente en la Ley 7/1996, de 15 de enero, de comercio minorista. Entre estas normas, destacan las relativas a los contratos de franquicia, desarrolladas mediante el Real Decreto 201/2010, de 26 de febrero, por el que se regula el ejercicio de la actividad comercial en régimen de franquicia y la comunicación de datos al registro de franquiciadores. El objetivo de estas normas es proteger a los potenciales franquiciados frente a posibles abusos en forma de engaño sobre las características de las franquicias. La protección se materializa básicamente en torno a la información y, más concretamente, 
en la obligación de los franquiciadores de inscribirse en un registro público de franquiciadores y de suministrar a los potenciales franquiciados por escrito y con una antelación de veinte días antes de contratar una información básica sobre la correspondiente franquicia.

Se trata de normas administrativas de derecho público, y no de normas contractuales de derecho privado, por lo que su infracción se sanciona mediante multas, sin que los tribunales hayan admitido efectos civiles a tales incumplimientos, rechazando con carácter general que sean motivo de anulación del contrato. Además, la Administración no se ha mostrado nada activa en el ejercicio de su potestad inspectora y sancionadora en este ámbito.

\section{c) Normativa de derecho internacional privado}

Los contratos de distribución son a menudo contratos internacionales que vinculan a un proveedor multinacional que pretende distribuir sus productos en distintos países mediante distribuidores locales. Esta circunstancia plantea el problema de la determinación de la ley aplicable y la jurisdicción competente, lo que exige recurrir a la normativa de derecho internacional privado.

Respecto a la ley aplicable, es preciso tener en cuenta, en el ámbito comunitario, el Reglamento (CE) núm. 593/2008 del Parlamento Europeo y del Consejo, de 17 de junio de 2008, sobre la ley aplicable a las obligaciones contractuales (Roma I); y fuera del ámbito comunitario, el artículo 10.5 del Código civil. Y en relación con la jurisdicción competente, resulta aplicable en el ámbito comunitario el Reglamento (UE) núm. I2I5/20I2 del Parlamento Europeo y del Consejo, de 12 de diciembre de 20I2, relativo a la competencia judicial, el reconocimiento y la ejecución de resoluciones judiciales en materia civil y mercantil; y en el extracomunitario el art. 22 de la Ley Orgánica del Poder Judicial.

Estas normas de derecho internacional privado parten como regla general del principio de autonomía de la voluntad de las partes, bien sea de forma expresa o tácita, por lo que proveedor y distribuidor son libres de pactar la ley y los tribunales que consideren más convenientes. Pero llegar a un acuerdo no resulta nada sencillo, pues el conflicto de intereses surge de inmediato, dado que cada una de las partes estará interesada en atraer el contrato hacia su ley y jurisdicción nacional. Y el asignar la determinación de la ley a una de las partes y la de la jurisdicción a la otra no necesariamente resuelve el problema, porque en ocasiones bastará alejar la jurisdicción de una de las partes para hacer inviable de facto la protección que pueda atribuir la norma por el coste que supone su implementación. En este punto, vuelve a ser determinante el mayor poder negocial que suelen poseer los proveedores, lo que les llevará a imponer fácilmente la ley y los tribunales de su país.

En defecto de pacto entre las partes, los criterios establecidos en estas normas de derecho internacional privado suelen resultar, con carácter general y simplificando, en la aplicación de la ley y la competencia de los tribunales del país del distribuidor, porque suelen partir de una conexión con el contrato que se vincula a su ejecución. Esta circunstancia supone para el proveedor un aliciente más para imponer expresamente su ley y sus tribunales en el contrato. 


\section{Propuestas de regulación: ¿hacia una ley de contratos de distribución?}

\section{I. Una década repleta de proyectos fallidos (2006-2016)}

Desde hace ahora una década, se debate ampliamente en España sobre la conveniencia de aprobar una regulación legal de los contratos de distribución. Gobiernos y partidos políticos de distinto signo han promovido múltiples proyectos legislativos que, por un motivo u otro han fracasado. Todas las iniciativas legislativas parten de la necesidad de una norma que equilibre la asimetría existente entre proveedores y distribuidores, con el objetivo de evitar el riesgo de abuso y reducir de esta manera la abundante litigiosidad en la materia.

El antecedente más relevante es sin duda la "Propuesta de Anteproyecto de Ley de contratos de distribución", elaborada por la Comisión General de Codificación y publicada en 2006, que no llegó a tramitarse legislativamente pero sí ha servido en gran medida como base para los subsiguientes proyectos. En 2007, el Congreso de los Diputados encargó al Gobierno, mediante proposición no de ley presentada por el Grupo parlamentario catalán Convergència i Unió, realizar un estudio sobre la materia que concluyó con un exhaustivo "Informe sobre la problemática de los contratos de distribución" del Ministerio de Industria, Turismo y Comercio, publicado en 2009, y que recomendaba la aprobación de una regulación legal para impedir las situaciones de abuso, pero que al mismo tiempo debía ser una norma de mínimos respetando el principio de autonomía de la voluntad de las partes contratantes y la libertad de empresa. En 2008, la Federación de Concesionarios de Automoción promovió una iniciativa legislativa popular en forma de "Proposición de Ley de contratos de distribución", que sin embargo no alcanzó el número de 500.000 firmas de electores requerido por la legislación vigente para prosperar. En 2010, siguiendo la recomendación lanzada por el citado Informe de 2009, el propio legislador (mediante la Ley I/2010, de I de marzo, de reforma de la Ley 7/1996, de 15 de enero, de Ordenación del Comercio Minorista), lanzó un explícito mandato al Gobierno para proceder a regular el régimen jurídico de los contratos de distribución comercial.

Justo un año después, la Ley $2 / 20$ I I, de 4 de marzo, de Economía Sostenible, modificaba la LCA para incorporar una sorprendente regulación de los contratos de distribución de vehículos automóviles e industriales. El texto de la reforma, que provenía del sector de los concesionarios, no seguía la recomendación de buscar una regulación de equilibrio entre los sectores afectados, y por el contrario proveía a los distribuidores una protección que era incluso superior a la que la propia LCA concede a los agentes. Esta situación causó tal revuelo que, apenas pasado un mes, en una de las siguientes leyes aprobadas, la Ley $7 / 20$ II, de II de abril, de Sistema de Pagos, se desactivó la polémica reforma de una forma un tanto peculiar, porque sin derogarla expresamente, se dejó en suspenso estableciendo que "hasta la entrada en vigor de la Ley de contratos de distribución", dicha reforma "no será aplicable y no producirá efectos jurídicos", incluyendo un nuevo mandato del legislador al Gobierno para remitir a las Cortes un proyecto de ley de distribución en el plazo de seis meses, y para presentar a las asociaciones del sector de la automoción un código de buenas prácticas.

Después de este sonado fiasco, el Gobierno presentó finalmente un "Proyecto de Ley de contratos de distribución", publicado en junio de 20II, que sin embargo decayó por finalización de la Legislatura. Iniciada la siguiente Legislatura, con cambio de Gobierno, el Grupo parlamentario socialista presentó, ahora desde la oposición, una "Proposición de Ley de contratos de distribución" prácticamente idéntica al anterior Proyecto, que se publicó en diciembre de 201 l y que no llegó a aprobarse. Conviene decir 
que el Proyecto había recibido la crítica de la Comisión Nacional de la Competencia, que alertaba del "peligro de una «sobreregulación» que, en el intento de equilibrar las relaciones entre las dos partes involucradas en la relación distributiva, reduzca en exceso la efectividad del principio de libertad de pactos consagrada en el propio texto del APL, de una manera innecesaria y desproporcionada en atención al objetivo perseguido", restringiendo excesivamente la competencia y la libertad de empresa y de organización de los sistemas de distribución. (Informe IPN 57/II de la Comisión Nacional de la Competencia, sobre el Anteproyecto de Ley de modificación de la Ley del sector eléctrico, de 25 de mayo de $201 \mathrm{I}$.

El último gran intento frustrado de regulación de los contratos de distribución llama todavía más la atención por la magnitud del proyecto normativo en que se inscribe y por la brusquedad con la que ha decaído. En efecto, hace ahora justamente una década el Ministerio de Justicia encargaba a la Sección de Derecho Mercantil Comisión General de Codificación la elaboración de un nuevo Código Mercantil. Tras cinco años de trabajo, este mandato culminó en 2013 con la presentación de una ambiciosa "Propuesta de Código Mercantil" que proyectaba modernizar y recopilar en un único texto jurídico toda la legislación mercantil, no solo la contenida en el ya desfasado Código de Comercio, sino también la reflejada en la abundante legislación especial en la materia.

En sus cerca de dos mil preceptos de este Código Mercantil, se incluyen numerosas novedades entre las que el propio Gobierno destaca la relativa a los contratos (Libro V), y muy especialmente, la de los contratos de distribución (arts. $\mathrm{XX}$ ), que se inscribe dentro de la categoría de los contratos de colaboración (Título IV), en la que se incluyen también otros contratos ya regulados, como el de comisión y de agencia, y otros atípicos aunque difundidos en la práctica, como el propio contrato de distribución y los contratos estimatorio, de mediación mercantil, de admisión a subasta pública y de participación. Sobre esta base, el texto propuesto incorpora una regulación del contrato de distribución similar a la proyectada en otras propuestas anteriores y, en concreto, prácticamente idéntica a la Propuesta de 2006.

Sin embargo, esta propuesta de regulación del contrato de distribución ni siquiera sobrevivió la primera ronda de negociaciones con instituciones públicas y operadores privados, pues decayó en su totalidad de forma abrupta excluyéndose de las materias finalmente recogidas en el "Anteproyecto de Ley de Código Mercantil" aprobado en mayo de 20l4. Y todo ello sin que se exista una explicación oficial de esta exclusión, aunque con carácter general se ha mencionado como motivo, aplicable también a otras exclusiones, la complejidad que supondría aunar los intereses de los sectores económicos afectados. En todo caso, el propio Anteproyecto ha decaído en su conjunto, pues terminada la Legislatura, es preciso que se reinicie el impulso gubernamental para revivir esta monumental iniciativa.

Resulta ilustrativo que el propio Consejo de Estado, en su dictamen núm. 837/20l4 sobre el Anteproyecto de Código Mercantil, aprobado por el Pleno en enero de 2015, haya dedicado una especial atención a este tema para criticar duramente la exclusión de los contratos de distribución de dicho Anteproyecto y recomendar encarecidamente su inclusión en el futuro Código, dada su importancia en el tráfico económico. Literalmente, ha querido subrayar que "la evidente dificultad que reviste codificar el contenido de contratos de naturaleza tan diversa como los que pueden incluirse bajo la rúbrica general de «contratos de distribución» no constituye, a juicio de este Consejo, excusa suficiente para postergar la aprobación de una regulación legal que ha sido ya formalmente anunciada por el legislador y cuya necesidad ha sido subrayada en ocasiones por la propia jurisprudencia", todo ello sin dejar de reconocer que la regulación proyectada ha sido "tan aplaudida como criticada". 


\subsection{Claves de la regulación proyectada: ¿normas imperativas o dispositivas?}

Los distintos proyectos de regulación de los contratos de distribución poseen en esencia un cuerpo base relativamente similar, sin perjuicio de algunas diferencias entre ellos, que aun siendo puntuales no dejan de ser significativas. En concreto, el esquema se estructura en cuatro bloques: primero, unas disposiciones generales, en las que esencialmente se enumeran y definen las modalidades contractuales incluidas y excluidas de la regulación; segundo, la formación del contrato, con especial referencia a deberes precontractuales de información a favor de ambas partes y a la potestad de solicitar la formalización por escrito del contrato y los efectos de su negativa; tercero, el contenido del contrato, en el que se detallan las obligaciones de las partes (por ejemplo, los objetivos comerciales, la compra mínima, la exclusiva territorial, la actividad publicitaria, etc.), así como el régimen de cesión de contrato; y, finalmente, la extinción del contrato, abordando sus causas y sus efectos patrimoniales, básicamente en forma de las indemnizaciones por inversiones y por clientela.

En algunos aspectos, los mencionados proyectos siguen de cerca la legislación del contrato de agencia, particularmente en materia de extinción contractual, confirmando la doctrina jurisprudencial de la aplicación analógica antes comentada. Pero en otros muchos aspectos aportan significativas novedades, algunas de las cuales podrían ser trasladables al contrato de agencia, como por ejemplo las relativas a los objetivos mínimos o a la subsanación de incumplimientos.

Sin duda, la piedra angular de la regulación proyectada reside en su configuración como imperativa o como dispositiva. El alcance de esta regulación depende de su configuración, pues si se diseña en términos meramente dispositivos puede ser fácilmente desactivada mediante un pacto en contra, lo que en la práctica puede traducirse en una escasa o nula eficacia. Por otra parte, no necesariamente debe configurarse como imperativa o dispositiva, sino que puede ser imperativa en unos aspectos y dispositiva en otros. Se trata de una cuestión que, como se recordará, ha sido objeto de profunda reflexión en los diversos informes que analizan los distintos proyectos, especialmente en el del Ministerio de Industria, Turismo y Comercio, así como en el de la Comisión Nacional de la Competencia.

Una y otra configuración posee ventajas e inconvenientes. La imperatividad, vigente como hemos visto para el contrato de agencia, resulta eficaz para prevenir los abusos derivados de la asimetría negocial, pero puede constituir una solución demasiado rígida para adaptarse a la diversidad de escenarios y modalidades contractuales tan propia de la distribución comercial. Por su parte, la configuración dispositiva, que es además la aplicable en general a todos los contratos, goza de una enorme flexibilidad sirviendo de régimen supletorio sin perjuicio de que las partes puedan pactar otro régimen distinto que se adapte mejor a sus necesidades, pero al mismo tiempo no resulta eficaz para atajar los posibles abusos, ya que puede fácilmente eludirse mediante un pacto en contra.

A pesar de la trascendencia del tema, los distintos proyectos hacen verdaderos ejercicios de funambulismo, con mayor o menor fortuna, para evitar decantarse decididamente por una u otra calificación, intentando mantener así la mayor equidistancia posible entre los intereses en conflicto. En esta línea, es ilustrativa la Propuesta de 2006, en la que se afirma que se "pretende conjugar, en la medida de lo posible, los principios de libertad de empresa y autonomía de la voluntad y de tutela de la parte más débil de la relación contractual, que, por lo general, suele ser el distribuidor". En una dirección similar, el Proyecto y la Proposición de $201 \mathrm{l}$ parecen, por un lado, promover el carácter dispositivo de la regulación, al definir entre sus objetivos básicos el de ofrecer "un régimen supletorio mínimo ante la 
ausencia de previsión contractual por las partes", incluyendo además la "libertad de pactos" entre sus principios rectores; pero, por otro lado, sus preceptos se construyen mediante estructuras claramente imperativas (por ejemplo, "deberán”). Por su parte, la Propuesta de Código Mercantil menciona expresamente que su regulación "se ha configurado como imperativa para favorecer a la parte más débil de la relación contractual, que suele ser el distribuidor o comercializador, especialmente cuando se trata de las pequeñas y medianas empresas", pero parece ceñir dicha configuración solo al régimen sobre "conclusión del contrato".

\section{Tendencias normativas en el ámbito internacional}

\section{I. Visión general del Derecho comparado}

El panorama normativo en materia de contratos de distribución existente en España responde, en líneas generales, a lo que sucede en buena parte de los países, especialmente en los Estados Miembros de la Unión Europea. En todos estos Estados existe una legislación sobre el contrato de agencia, que se halla armonizada producto de la vigencia de la Directiva de 1986, y la mayoría de ellos carecen de una regulación específica de los contratos de distribución, aunque los tribunales suelen aplicar por analogía la normativa de la agencia a estos contratos. La excepción, que siempre se destaca, es el caso de Bélgica, que por su tradición de país de distribuidores, posee desde 196I una regulación legal sobre la terminación unilateral de los contratos de distribución exclusiva, ahora incorporada en el vigente Código de Derecho Económico, que ofrece una significativa protección a los distribuidores.

Fuera de las fronteras europeas, es frecuente la ausencia de una regulación especial, no ya del contrato de distribución, sino incluso del contrato de agencia, quedando estos contratos sujetos al régimen general de los contratos y por tanto al principio de autonomía de la voluntad, de modo que agentes y distribuidores no suelen gozar de una tutela reforzada. Esta situación se produce especialmente en los países de tradición anglosajona, donde se fomenta especialmente la autonomía negocial de las partes contratantes.

Dicho lo anterior, se observa últimamente una cierta tendencia a aprobar normas legales reguladoras de los contratos de distribución, incluido el contrato de agencia, siguiendo a menudo el modelo del Derecho comunitario. Tal es el caso, por ejemplo, de Argentina, que ha aprobado recientemente un nuevo Código civil y comercial (Ley 26994, de I de octubre de 20I4, con entrada en vigor en agosto de 20I5), que incluye una regulación legal de los contratos de agencia, concesión y franquicia.

\subsection{Armonización internacional del Derecho de contratos mediante soft law}

La creciente tendencia hacia la globalización ha impulsado en los últimos años una tendencia a armonizar y modernizar la normativa aplicable a los negocios internacionales y, en especial, en materia de contratos como uno de los instrumentos más habituales en el tráfico mercantil. Ante la dificultad que supone llevar a cabo esta armonización mediante los tradicionales convenios internacionales, esta tendencia se ha desarrollado principalmente a través de fórmulas del denominado "soft law", es decir, mediante recomendaciones o códigos de conducta elaborados por organismos e instituciones internacionales que no poseen carácter vinculante por no tratarse de reglas de carácter normativo ("hard law"), pero que ejercen cada vez una mayor influencia en la medida en que son voluntariamente acogidas por los Estados 
como modelo para elaborar su propia legislación o como criterio interpretativo de la misma; o bien por los particulares en sus relaciones privadas cuando la han elegido como ley aplicable.

Entre estos instrumentos paranormativos destacan los "Principios sobre los contratos comerciales internacionales” elaborados por Unidroit, el Instituto Internacional para la Unificación del Derecho Privado. Aunque estos Principios, que cuentan ya con su tercera edición de 2010 (después de las de 1994 y 2004), estando en fase de preparación su cuarta edición de 2016, vienen referidos a los contratos con carácter general y no a específicas modalidades contractuales, sus reglas resultan de gran interés en materia de contratos de distribución, pues afectan a materias clave de estos contratos como son las de su formación, interpretación, cumplimiento y, sobre todo, terminación. De hecho, la Propuesta de Código Mercantil antes analizada sigue abiertamente los criterios establecidos en estos Principios Unidroit. Más específicamente, el Unidroit ha elaborado también una Ley modelo sobre la divulgación de la información en materia de franquicia, de 2002, que ha inspirado también a nuestro legislador a la hora de reformar el régimen de la franquicia.

En el ámbito de la Unión Europea también se ha desarrollado una intensa labor armonizadora del Derecho de contratos, que persigue el ambicioso objetivo de elaborar un Código europeo común de Derecho privado. Esta labor, que tiene sus antecedentes ya a finales en los años ochenta, ha cristalizado en diversos hitos, como son, primero, los "Principios de Derecho Contractual Europeo", de 2000, también conocidos como Principios Lando; posteriormente, en términos todavía más ambiciosos, los "Principios, definiciones y reglas modelo de Derecho privado europeo", denominados "Borrador de Marco Común de Referencia” (Draft Common Frame of Reference) de 2009, cuya finalidad es establecer los principios compartidos del derecho contractual europeo así como una terminología común; $y$, más recientemente, la "Propuesta de una Normativa Común de Compraventa Europea", de 201 I.

Tanto los Principios, como el Marco Común, incorporan reglas específicas relativas a los contratos de distribución. En concreto, el Marco Común, en su Libro IV (relativo a contratos específicos), Parte E (relativo a agencia comercial, franquicia y distribución), incluye una serie de disposiciones comunes a estos tres contratos, sobre todo referidas a los deberes de información precontractual y la extinción del contrato, para desarrollar a continuación reglas específicas de cada una de estas tres modalidades, referidas principalmente a las obligaciones de las respectivas partes contractuales.

\section{Reflexión final}

Son diversos los argumentos que justifican la conveniencia de aprobar una normativa legal específica de los contratos de distribución que regule el contenido obligacional de estos contratos, así como su extinción: la habitual asimetría negocial que subyace en los mismos y que plantea riesgo de abusos, la conflictividad que genera su extinción y que deriva en una creciente litigiosidad, la frecuencia de su oralidad y de su incompleto clausulado contractual, la ausencia de normas generales de referencia que den respuesta clara a sus especificidades, su importancia económica, etc.

A pesar de existir argumentos en contra de su regulación, no resultan suficientemente convincentes para no llevarla a cabo, puesto que regular parece generar mayores beneficios que costes. La rigidez que puede plantear una regulación que no se adapte a la variedad de supuestos y modalidades contractuales, así como a su cambiante evolución, puede superarse introduciendo elementos de flexibilidad en la regulación, existiendo siempre la posibilidad de reformas puntuales que subsanen estos inconvenientes. 
El hecho de que la mayoría de países carezcan de reglas específicas reguladoras de los contratos de distribución no es, per se, un argumento para defender la pasividad normativa, teniendo en cuenta los problemas que genera la misma.

Más complejo resulta decidir si dicha regulación debe configurarse en términos imperativos o dispositivos, puesto que ambas posiciones se amparan en sólidos argumentos. En todo caso, como criterio orientativo parece que la introducción de normas imperativas debe ser algo excepcional, teniendo en cuenta el principio general de la autonomía de la voluntad de las partes que rige en el ámbito contractual, por lo que su aprobación como tales exige identificar las necesidades específicas y justificar su imperatividad, que debe fundarse en un claro desequilibrio negocial. La prudencia indica que cabe comenzar en una primera fase con una regulación esencialmente dispositiva, que cumpla la importante función de régimen supletorio en defecto de pacto, para plantearse luego según resulte la aplicación de dicha regulación si realmente cumple también una función preventiva de abusos negociales. Debe tenerse en cuenta que los déficits que pueda plantear una normativa excesivamente laxa, pueden puntualmente ser resueltos por los tribunales a la vista del caso concreto, aunque esta solución no es la más satisfactoria, porque no fomenta la predictibilidad de las decisiones judiciales.

Mientras tanto, operadores y tribunales tienen a su disposición materiales normativos de gran utilidad, particularmente todos los valiosos instrumentos de soft law elaborados por los organismos modernizadores y armonizadores del Derecho internacional de los negocios. Cabe incluso desarrollar otros instrumentos paranormativos que tienen todavía recorrido, como son los códigos de conducta. Además, la propia Propuesta de Código Mercantil, y los otros proyectos normativos, pueden servir como útil herramienta para los operadores en la formación del contrato y para los tribunales como criterio interpretativo e integrador de las lagunas normativas. Quizá debería promoverse también una "cultura de la autoprotección”, en virtud de la cual los propios operadores tomen conciencia de la necesidad de negociar una protección activando los múltiples mecanismos contractuales a su disposición. En conclusión, se trata de un reto difícil, pero en modo alguno inasumible, y más si se plantea como una labor progresiva que necesita al menos comenzar cuanto antes para ir evolucionando según avance, sin que la pasividad parezca una respuesta sensata.

\section{Lista de referencias bibliográficas}

Alonso Soto, R. (20I5). La regulación proyectada de los contratos de distribución en la Propuesta de Código mercantil. En M.J. Morillas Jarillo, M. P. Perales Viscasillas, L. José Porfirio Carpio, Estudios sobre el futuro Código Mercantil: libro homenaje al profesor Rafael Illescas Ortiz (Pp. II63-II75). Madrid: Universidad Carlos III,.

Alonso Soto, R., Jordá Capitán, E., Viera González, A.J., Echebarría Sáenz, J.A., Ruiz Peris, J.I. (20I3). La reforma de los contratos de distribución comercial. Madrid: La Ley.

Alonso Ureba, A., Velasco Sanpedro, L.A., Alonso Ledesma, C., Echebarría Sáenz, J.A., Viera González, A.J. (2010). Los contratos de distribución. Madrid: La Ley.

Cañabate Pozo, R. (20/4). Nueva perspectiva de regulación de los contratos de distribución. Revista Aranzadi Doctrinal 3/20I4, pp. 23 a 42. 
Carbajo Gascón, F. (20I5). Los contratos de distribución en las propuestas armonizadoras del derecho contractual europeo. Valencia: Tirant lo Blanch- Universidad de Salamanca.

Cruz Rivero, D. (20I5). La regulación proyectada (y fracasada) de los contratos de distribución. En M.J. Morillas Jarillo, M. P. Perales Viscasillas, L. José Porfirio Carpio, Estudios sobre el futuro Código Mercantil: libro homenaje al profesor Rafael Illescas Ortiz (pp. I262-I288.). Madrid: Universidad Carlos III

Echebarría Sáenz, J.A. (20I2). Problemas de política jurídica y de técnica jurídica en la regulación de los contratos de distribución. Revista de Derecho de la Competencia 10/2012, 15-53.

Olivia Blázquez, F. (20I4). El Anteproyecto de Código Mercantil en el contexto del proceso internacional de unificación del Derecho privado de los contratos. Revista de Derecho Civil, vol. I, 3/20I4, 3766.

Pérez-Serrabona, F.J. (2015). Franquicia y contratos de distribución en el Anteproyecto de Código Mercantil. En M.J. Morillas Jarillo, M. P. Perales Viscasillas, L. José Porfirio Carpio, Estudios sobre el futuro Código Mercantil: libro homenaje al profesor Rafael Illescas Ortiz. Madrid: Universidad Carlos III (pp. I667-I686).

Vázquez Albert, D. (20l0). Los contratos de distribución comercial: novedades legislativas y jurisprudenciales. Valencia: Tirant lo Blanch. 